WellBeing International

WBI Studies Repository

1985

\title{
Veterinary Conduct and Animal Welfare
}

H. Rozemond

Veterinary Public Health Inspectorate

Follow this and additional works at: https://www.wellbeingintlstudiesrepository.org/acwp_vsm

Part of the Animal Studies Commons, Bioethics and Medical Ethics Commons, and the Other Veterinary Medicine Commons

\section{Recommended Citation}

Rozemond, H. (1985). Veterinary conduct and animal welfare. In M.W. Fox \& L.D. Mickley (Eds.), Advances in animal welfare science 1985/86 (pp. 255-265). Washington, DC: The Humane Society of the United States.

This material is brought to you for free and open access by WellBeing International. It has been accepted for inclusion by an authorized administrator of the WBI Studies Repository. For more information, please contact wbisr-info@wellbeingintl.org.

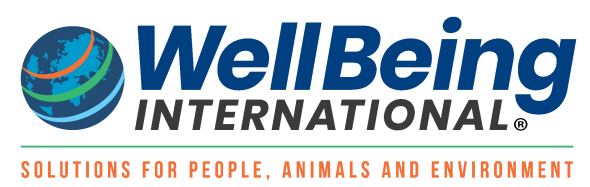




\section{VETERINARY CONDUCT AND ANIMAL WELFARE*}

\section{H. Rozemond}

Chief Inspectorate

Veterinary Public Health

Section Animal Experimentation

P.O. Box 439

2260 AK Leidschendam,

The Netherlands

\section{Introduction}

In 1969 I had the honor to deliver a lecture to the 116th Annual Congress of the Royal Netherlands Veterinary Medical Association concerning the activities of veterinarians involved in herd health (Rozemond 1970). My lecture aimed to challege the veterinary aspects of a system of animal husbandry at that time new to Dutch circumstances; the system characterized by enlargement of scale and by species specialization. The thesis of this rather technical lecture read: "We have to build a new barn with a good climate." At that time, books such as Animal Machines by Ruth Harrison (1964), in which intensive rearing of farm animals was criticized, had barely attracted attention. That seemed unnecessary indeed: A Dutch agricultural journal had established Harrison as an adherent of an old-fashioned, useless and folkloristic belief. Much has changed since that time. The technical way of dealing with animals, not only in intensive rearing but also in other areas, is now facing increased criticism.

This paper is a lecture presented to the same Association but fifteen years later: the 131st Annual Congress in 1984. This second presentation contemplates two points: First, it tries to indicate how this criticism has gradually emerged and a historical outline is put forth of the development of veterinary medicine, a differentiation being made between a

"Translated from Tijdschrift voor Diergeneeskunde 1985, 110:21-30. 
mythical, a technical, and a critical approach. Second, a discussion of how veterinarians have to associate themselves with this criticism in their professional conduct is presented. This discussion is necessary for two reasons. Veterinarians have increasingly become aware that they bear a professional responsibility not only for animal health but also for animal welfare; and, veterinarians are expected to give their views in concrete situations.

\section{The Mythical Attitude}

In a number of publications, the German veterinary historian Hausmann (1982a, b, 1984) has sketched the outlines of the centaur Cheiron, father of European medical and veterinary practice, a being from old mythical days: son of a god (Kronos) and a woman (Philyra); half man, half horse. These and other allurements of the Cheiron legend must not tempt us to doubt his historicity. The excavation of Troy was crowned with success because Schliemann took acknowledgement of the poems of Homer. Hausmann did the same to Cheiron. He made it plausible that Cheiron lived around 1270 B.C. in Mileai in the Greek Pelion mountains. Hausmann also asserts he can indicate the cave where Cheiron lived and worked.

During Cheiron's time, the cave was visited by people with various ailments: wounds, genetic disorders, diseases caused by summer heat or winter cold. Cheiron exorcized his patients with tranquilizing incantations, treated their wounds with herbs or with the scalpel. His care not only concerned man but also animals. This is evident from the history of the dogs of the Greek hero Aktaion. These animals, after the death of Aktaion, inconsolably searched for their master and eventually turned up at the cave of Cheiron, who allayed their grief by modeling a statue of their killed master.

The knowledge of Cheiron, we must assume, was experience-based. Man was linked with nature, partook with it, put to use the tools at hand or which were in sight, or performed what the gods instigated. Cheiron did not keep his knowledge to himself. He founded a school, passed knowledge to others, who were honored afterwards as gods and heroes in old Hellas: to Asklepios, to whom he taught medicine; to Hygieia, the goddess of health; to Panakeia (panacea); to Orpheus, to whom he also gave musical instruction; to Achilles, who learned from Cheiron the skills of hunting and foraging. In this way, Cheiron emerges from history as a man with universal knowledge and as one with his surroundings. In mythical times, the performance and technical skill of man were determined by his knowledge of, and his experience with, nature. 
We may characterize this mythical attitude with some catchwords. Man participates in his environment; he uses the forces of nature and strives for a certain well-being. In summary, he lives with the notion "that" culture exists.

There is no reason to look down upon this mythical culture with self-conceit; but natural knowledge and natural experience can harden to magic and witchcraft. It has been pointed out that veterinary knowledge also was available in the middle ages, but at that time this knowledge was more often than not made up of a gathering of prescriptions, which were for centuries long transcribed, appended, and mutilated. Theriacum and asafoetida were the highest wisdom, and also elixirs, with up to sixty not too palatable ingredients, talismans, spells, uroscopy, cupping, leeches, holy water, relics, and saints. Till far into our century, the German rhyme was accepted: "Weisz man nicht mehr wie, was und warum, dann nimmt man Jod-jodkalium."* Dutch seventeenth century paintings conspicuously give an impression of the mistrust to prevailing (veterinary) medicine. The quack was a favorite subject for such painters as Jan Steen (1626-1679) and contemporaries (figure 1).

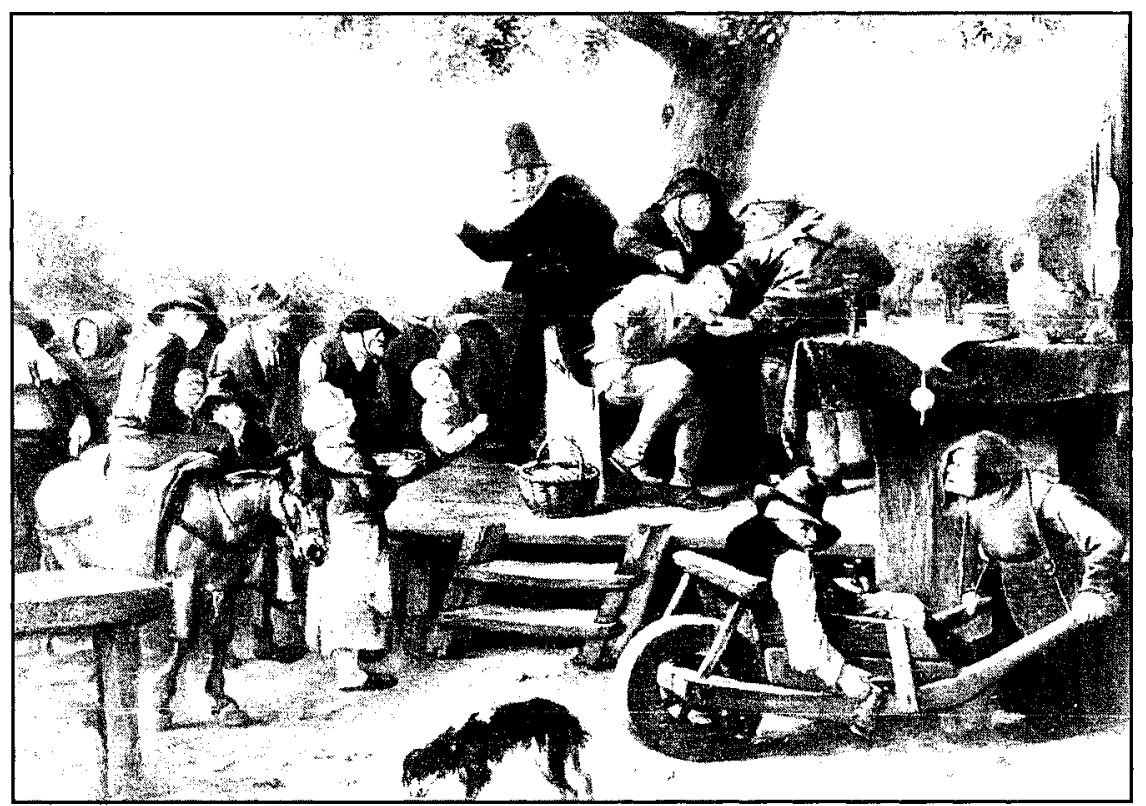

Figure 1. Jan Steen (1626-1679): The Quack. Rijksmuseum, Amsterdam.

\footnotetext{
*"When not is known who, what or why potassium iodide you may try." (Author's translation)
} 


\section{The Technical Attitude}

In the same period, however, other Dutch painters, e.g. Rembrandt van Rijn (1606-1669) were commissioned, mostly by City Guilds, to depict an "Anatomical Lesson." Such paintings portray a group of persons gathered around a prosector demonstrating the muscles and internal organs of a corpse. These paintings illustrate the changes that took place. Man not only makes use of the superficial but searches within the body. He has dissociated himself from his environment; he turns away from the familiarity of the mythical and focuses on observation. Experimentation has appeared; data are arranged, analytical, quantifying, systematical, controllable, causal. Science crops up and begins to flourish. A new age has emerged. The anatomists take the lead. They give descriptions of the substratum. Mondino de'Luzzi (fourteenth century) is the first in the Renaissance to perform dissections, not only of dogs and pigs but also of men. Leonardo da Vinci (1452-1519) and Albrecht Dürer (1471-1528) make their famous sketches. Andreas Vesalius publishes in 1543 the first standard work on human anatomy: De Humani Corporis Fabrica. Veterinary medicine barely lags behind: Carlo Ruini's Anatomia del Cavallo appears fifty-five years later. The foundations of a new science are laid. The painting of Cornelis de Man (1681) depicting an anatomical lesson to a group of scientists in the

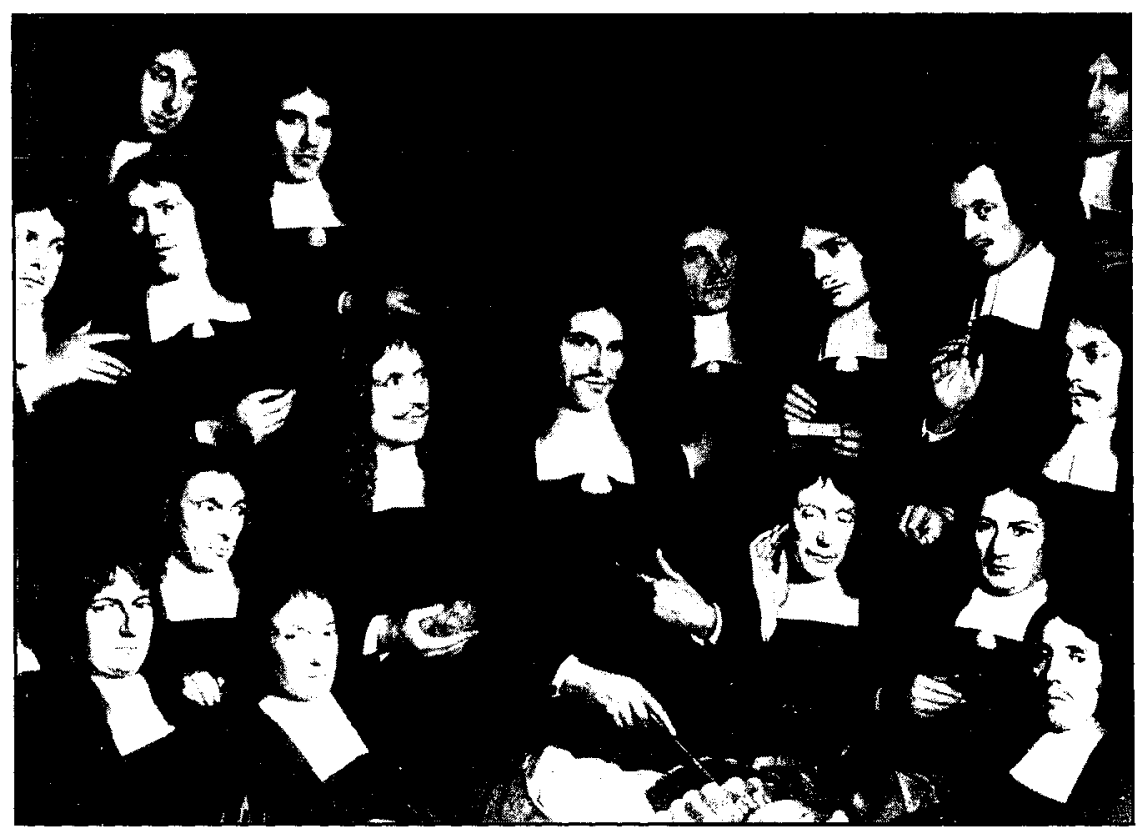

Figure 2. Cornelis de Man: Anatomical Lesson of Isaac 's Gravensande. Prinsenhof Museum, Delft. 
small Dutch city of Delft (figure 2) characterizes the progress and dissemination of modern science albeit at Delftian level. However, this level must not be underestimated. In the painting, standing next to prosector Cornelis 's Gravesande, is a man wearing a peruke, Antoni van Leeuwenhoek, the father of microbiology and correspondent to the Royal Society of London for Improving Natural Knowledge. Reinier de Graaf, a contemporary Delftian physician, just missed appearing in the setting, as he died eight years before completion of the painting. De Graaf was the first to understand the significance of appearances on the ovaries which are now known as the graafian follicles. He was also able to perform fistulae to the pancreatic gland of dogs (without analgesics!) and to keep those animals alive (without antibiotics!). Unprecedented possiblities emerged. A wave of knowledge, not naive but scientific, spread throughout Europe. Ingenuity, medical and nonmedical, yielded results and new technical possibilities. True, it needed time and immense energy. For example, to reach today's level of open heart surgery, it has been calculated that more than four thousand essential investigations had to be performed (Comroe and Dripps 1976). But the energy was available and also the money. Veterinary medicine again had not lagged behind. This may be deduced from the fact that the 1984 volume of the Veterinary Bulletin mentions more than eight thousand publications.

This representation - maybe it is better to speak of an accelerated film-gives an impression of a second cultural attitude, i.e., that of investigation and technique. Man no longer participates in his setting nor only uses what is at hand, but he takes distance; he devises principles and possibilities to interfere in nature. Technical ingenuity is placed into motion; production becomes the slogan; prosperity the aim. Man is no longer satisfied by ascertaining "that" he participates in culture; he seeks to answer the question, "what" can be done to develop culture. When we look about, the results seem to be nothing short of staggering indeed: a new barn, a good climate.

\section{The Critical Attitude}

It may be good to stop the film for just a moment. As a schoolboy, I learned that farming was a means of subsistence; today we speak of "agri-business." That sounds quite different and we observe that some animals in this business show severe and enduring behavioral aberrations. When referring to animal experimentation we speak of "animal models." In the Netherlands, 1.3 million of such models are used annually. We, as veterinarians, are able to geld, to spay, to amputate, to devocalize, to extirpate, to canulize, to declaw, to debeak, and to pinion. 
Little by little we are able to do anything with animals, thanks to our ingenuity, and we do it when asked. Apart from the veterinary scene are also examples of technical possibilities and of their adversities. Acid rain, water pollution, nuclear weapons, and euthanasia, formerly far-off or unknown words are nowadays familiar eye-openers. They are catchwords for the crushing of our "what" culture, resulting from the unbridled self-reliance of the technical attitude.

Thus, technicians are summoned to solve these problems and when this seems to fail we clamor for legislation, in the way of: "Vivisection? A law! Continued vivisection? Higher fines!" But it becomes ever clearer, that it is not the technicians nor the legislators who can unravel our modern problems. What we need, is a new approach to culture, a third attitude. The principle question is no longer what we may conceive or perform: that is almost infinite. More important has become the question of how our judgement is on the technical potentialities we have and how we should handle our cultural inheritance. We can produce very well, but we must learn to benefit from it in a meaningful way. For the issue is not prosperity, but welfare. Obviously, we must learn to yield from distance (which causes disruption) and to concern us more with the equilibrium of involvement and companionship. The critical element which was kept out of my 1969 lecture was: "for what" functions our culture, "for what" functions veterinary medicine, "for what" function veterinarians.

It can be concluded that there is a distinction between the various attitudes towards culture. They are shown in the following diagram.

\begin{tabular}{lcc} 
myth/nature & research/technique & judgment/criticism \\
\hline participation & distance & relation \\
use & production & utilization \\
well-being & prosperity & welfare \\
"that" & what" & for what" \\
\hline
\end{tabular}

In addition, it can be reasoned that transition from one attitude to another usually occurs when culture is stumbling. In the above treatise this is marked by the prevailment of magic and by the surplus of technical influence respectively. However, transition does not emerge unless its need is recognized. A blind spot can prevent us from focusing on jammed circumstances. Eye-openers can be useful at this time.

\section{Animal Welfare}

One of the subjects for which we have a better appreciation is the welfare of animals. Since Cheiron, the veterinary profession has developed to an art of healing, alleviation, and prevention. We become increasingly aware that it also has to be attentive to the harmonious 
existence of animals both ethologically and physiologically. Veterinarians often work with animals in suboptimal circumstances, such as bare pens, plastic boxes, and apartment buildings. There, animals become resources, tools, and victims. Veterinarians should also care for the welfare of these animals to the extent possible.

Empathy to animals increases when they are less looked upon as tools or "whats." Other viewpoints have arisen, e.g. Schweitzer's idea of reverence for life (Schweitzer 1984) or Singer's principle of conditional equivalence (Singer 1975). The veterinary profession and each individual veterinarian has to reflect on such concepts in order not only to find the right attitude but also to meet the responses of society (Fox 1984). Veterinarians are expected to have a knowledge of these matters.

\section{Professional Duties}

Among the branches of the Royal Netherlands Veterinary Medical Association an inquiry was held concerning welfare bottlenecks in everyday practice. The responses can be placed into three categories.

First, there are difficulties with regard to careless or imperfect veterinary-technical performance. Veterinarians appear to experience difficulties with such interventions as castration, herniotomy, plastic surgery on teats, teeth-corrections, removal of warts, treatment of prolapsus ani et recti, use of coercive means, stunning for slaughter, choice of euthanasia methods.

The second group entails problems which result from nonmedical desires of individual owners with regard to an animal. To this category belong declawing, devocalization, partial tongue resection, penis deviation, tail docking, ear cropping, neurectomy, (sophisticated operations), euthanasia and its reverse, needless suffering, e.g., of disabled animals.

A third category is formed by the problems resulting from decisions made on a level beyond the direct relation of veterinarian/owner. At times tasks have to be performed at the instigation of employers or governmental agencies. Such problems relate to intensive animal farming, breeding of animals with genetic abnormalities, ritual slaughter, animal experimentation, or the like.

With regard to the first category, it has to be admitted that pain release or sedation are not always attended to in an optimal way in practice. Partly, these problems can be prevented by better application of available know-how. Veterinarians must possess this know-how and put it into practice. Neither economy nor convenience are motives to trifle with this principle. However, when technical knowledge is not available, specific research should be initiated.

Veterinary handbooks are not the place to find solutions for the second and third category of problems, for those problems are caused 
by technological successes, rather than by casual failures. It was the successes which brought us in a situation in which we can perform "everything." The tragedy is that this omnipotence results in disturbed relations. So, it is doubtful whether additional technology is the suitable means to do away with this disturbance. The most meritorious thing to do is to explore disturbed relations, to map them and to subsequently seek solutions in a creative and inventive way.

The endeavor to explore these relations is expressed by Boon (1983) in his definition of animal mistreatment as "the harming of an animal's welfare to a greater extent than is necessary to reach a meaningful (social) aim." This definition can be made operational by (1) a description of the use or intended use of the animal, (2) a description of the (direct and/or indirect) aim of the use, (3) a calculation or assessment of its social significance, (4) an assessment of its implications for the animal's welfare, (5) an assessment of alternatives, if any. In the end after a process of evaluation of this data and assessments (6) a judgement can (or cannot!) be made. Such a judgement can hold an accession, a conditional accession, a disclaimer or a suspended disclaimer.

In conclusion, our interrelationship with animals has to be incorporated in our society and culture. This means: not always for the benefit of economics, science or fashion, nor-granted-always in the interest of animals. Under discussion consequently comes the "for what" question. That question not only involves veterinary, medical, biological, or agricultural aspects, it also has religous, philosophical, ethical, juridicial, aesthetical, economical, sociological, historical, and political implications; in short, it is a human problem.

\section{The Balance}

The modern Dutch animal protection movement has understood that the "for what" question is a human problem. This movement is increasingly prepared to search for poised considerations. Here are some examples:

- membership of the Public Council of Veterinary Affairs, together with the Ministries of Agriculture and of Public Health, the Veterinary Association and organizations of farmers and industry;

- membership of the Committee on Health and Well-being of pet animals, together with the Veterinary Association;

- financial support of research into alternatives to animal experiments, at joint expense with government and industry;

- platform discussions with religious minority groups about ritual slaughter. 
These examples have two characteristics in common: (1) the readiness to seek for logical solutions and (2) the willingness to do so with those who are faced with the same problem, but in a different viewpoint.

This should also hold true for the veterinary profession. The veterinary profession cannot pretend to be able to solve all animal welfare problems independently. It must listen to other disciplines as well.

The discussions about the "for what" question in relation to the position of animals is rather recent. As mentioned earlier, the "what" culture, reckoning from the Mondino dissections up to modern heart surgery took more than six centuries. The "for what" question occupies our minds but a fraction of that period. So it is not surprising that we now are in the state of only seeking after the right attitude. In fact, we are now just living in the Mondino phase of substrata description: how is the relation man-animal; what is pain and distress; when does it come to infringement of animal welfare; how can it be measured; do animals have an intrinsic value, do they have rights; what about intercultural differences, i.e., religious or urban-versus-rural traditions, and animal welfare. Such reflections ultimately must lead to better understanding and to new values and standards in society and in the veterinary profession. The broader the basis on which these problems are discussed and the greater the aptitude brought in, the more valuable results may be obtained.

\section{Conscience}

This brings us back to the question whether a veterinarian, minding all circumstances, should concern himself with particular interventions when he is asked by animal owners or decision-makers to perform: declawing, practice in intensive farming, animal experimentation. Such a question may lead to tension between a conscience that speaks out and the interests of others. Veterinarians are paid to dedicate themselves to the interests of their commissioners. However, they must also pay attention to animal interests, an entity with peculiar objective and subjective aspects. Welfare of man and animal are sometimes conflicting. Be that as it may, to perform in an ethically correct manner requires conscious reasoning, every time a decision has to be made.

Freedom of action is determined by values and standards. In concrete situations they allow us to make selections from alternatives. How such selections are made, does not concern us here. The point here is that our actions can at times barely be reconciled with our values and standards. So we must ask ourselves inventive and creative questions, not only the "what" questions, but also the "for what" ones. In sorting the answers we may come to an agreement with ourselves: I should, or I should not, declaw. The question may be put, whether it is the 
responsibility of the veterinarian to decide in such questions. Is not the owner the first to be addressed? The answer is that both are involved. The veterinarian as well as the owner has to account for his own decisions and the consequences. If necessary, veterinarians should make that clear to owners.

Quite different is the situation when the veterinarian functions in a peculiar task or role. This applies when his or her tasks are part of a framework, e.g., in an employment or a legal setting. In such situations the interests and the decisions of the organization are conclusive and the logic of it is determined at that "higher" level. Here two options are open for the veterinarian. He or she can do his or her job under protest and use the utmost endeavors to bring change in the rules. In this way, participation is not necessarily a matter of disgrace although it may be a painful embarrassment. The other option is that participation is felt to be unacceptable. This can result in the decision to not participate and the acceptance of the painful consequences of that decision. It can be reproached that in this manner the treatise gets stuck in a micro-ethical exploration, in a scanning of the individual responsibility of a veterinarian and that the burden of pain is charged on his or her conscience alone. Isn't there something like professional ethics as a whole? It can be replied that it is very difficult to avoid individual pain, because pain is a subjective feeling and a signal, here in particular a signal of disturbed relations which everyone experiences in his or her own manner. In addition, this author is insufficiently authoritative to decide for his whole profession which values and standards should prevail in future veterinary conduct. However, we do have some statements and acknowledgements. It is good to remember the recommendations and decisions on animal welfare of the Federation of Veterinarians in Europe (FVE) (van Riessen 1982) and of the draft International Guiding Principles for biomedical research involving animals of the Council for International Organizations of Medical Science (CIOMS 1983). However, such declarations are not yet fully accepted in society nor in the profession. So when we want to come to a meaningful attitude - and I believe this to be necessary - then critical discussions have to proceed and be amplified. Professional associations of veterinarians can be an important platform for it.

The Dutch poet Willem Elsschot wrote the verse:

... want tussen droom en daad

staan wetten in de weg en praktische bezwaren.

(From dream to deed you meet restraining laws and practical objections.)

If this be true, we have to critically assess such obstacles, for the aim still should be: a new barn with a better climate. 


\section{Acknowledgements}

Translation of the original article was made possible by courtesy of the Editor of Tijdschrift voor Diergeneeskunde. The English version of this paper was improved tremendously by intelligent comments of Mr. R.P. Selman.

\section{References}

Boon, D. 1983. Nederlands dierenrecht. Arnhem, The Netherlands. Gouda Quint. B.V.

CIOMS 1984. Biomedical Research Involving Animals. Bankowski, Z. and Howard-Jones, N. eds. Council for International Organizations of Medical Sciences, Geneva.

Comroe, Jr., J.H. and Dripps, R.D. 1976. Scientific basis for the support of biomedical science. Science. 192:105-11.

Fox, M.W. 1984. Towards a philosophy of veterinary medicine. The Veterinary Record. 115:12-13.

Harrison, R. 1964. Animal Machines. London: Vincent Stuart Ltd.

Hausmann, W. 1982a. Ars Chironica, Antike Autoren über Cheiron. Dtsch. Tierärztl. Wschr. 89:407-11.

Hausmann, W. 1982b. Die medizinischen Höhlenschule des Cheirons. Berl. Münsch. tierarztl. Wsch. 95:94-5.

Hausmann, W. 1984. Cheiron. Eine weitere Sammlung und Auslegung von Zeugnissen. Dtsch. tierärztl. Wschr. 91: 24-6.

Riessen, H.A. van. 1982. Role of the Federation of Veterinarians in the EEC (FVE) in Animal Welfare. Anim. Regul. Stud. 3:145-52.

Rozemond, H. 1970. De veterinaire begeleiding van grote bedrijven Tijdschr. Diergeneeskd. 95:117-22.

Schweitzer, A. 1984. Die Ehrfurcht vor dem Leben: Grundtexte aus 5 Jahrzehnten. Beck, Munchen.

Singer, P. 1975. Animal Liberation. New York: Avon Books. 